\title{
IDENTIFICATION OF AEROSOL SOURCES IN SIBERIA AND STUDY OF AEROSOL TRANSPORT AT REGIONAL SCALE BY AIRBORNE AND SPACE-BORNE LIDAR MEASUREMENT
}

\author{
Antonin Zabukovec ${ }^{1}$, Gérard Ancellet ${ }^{1}$, Jacques Pelon ${ }^{1}$, J.D. Paris ${ }^{2}$, Iogannes E. Penner ${ }^{3}$, Grigorii \\ Kokhanenko ${ }^{3}$, Yuri S. Balin ${ }^{3}$ \\ ${ }^{1}$ Laboratoire Atmosphere Milieux, Observations Spatiales (LATMOS), CNRS, Sorbonne Université, \\ Université Versailles St Quentin, Paris, France \\ ${ }^{2}$ Laboratoire des Sciences du Climat et de l'Environnement, CEA-CNRS-UVSQ, Gif sur Yvette, France \\ ${ }^{3}$ Zuev Institute of Atmospheric Optics, Russian Academy of Sciences, Tomsk, Russia
}

\begin{abstract}
Airborne lidar measurements were carried out over Siberia in July 2013 and June 2017. Aerosol optical properties are derived using the Lagrangian FLEXible PARTicle dispersion model (FLEXPART) simulations and Moderate Resolution Imaging Spectrometer (MODIS) AOD. Comparison with Cloud-Aerosol Lidar with Orthogonal Polarization (CALIOP) aerosol products is used to validate the CALIOP aerosol type identification above Siberia. Two case studies are discussed : a mixture of dust and pollution from Northern Kazakhstan and smoke plumes from forest fires. Comparisons with the CALIOP backscatter ratio show that CALIOP algorithm may overestimate the LR for a dusty mixture if not constrained by an independent AOD measurement.
\end{abstract}

\section{INTRODUCTION}

Asian pollution and oil/gas flaring in Siberia have been identified as aerosol key sources, however the impact by these pollutants is poorly known. CALIOP or MODIS satellite observations provide valuable information about aerosol spatial distributions and optical properties may be compared with ground-based or airborne observations. Regional aerosol studies with CALIOP have been conducted for high latitudes [1], European Arctic [2], or the Arctic ice sheet [3], but no similar studies exist for Central Siberia.

\section{METHODOLOGY}

\subsection{Objectives and methodology}

Airborne backscatter lidar observations in Siberia were carried out and compared to CALIOP data using Level 2 Version 4 CALIOP aerosol data products [4] and Level 1 CALIOP attenuated backscatter processed at LATMOS [2] in order to assess CALIOP aerosol optical properties accuracy.

Aerosol types were characterized using the Lagrangian FLEXPART model, aircraft in-situ measurements, MODIS AOD and CALIOP aerosol vertical extent and depolarization in the source region. Biomass-burning emissions were identified using the daily fire radiative power (FRP) maps based on NASA Fire Information for Resource Management System (FIRMS) using MODIS [5] and the Visible Infrared Imaging Radiometer Suite (VIIRS) [6]. Only FRP $>0,05$ GW were taken into account.

\subsection{Aircraft campaigns}

The aircraft campaigns took place in July 2013 and June 2017. The four flight tracks for each campaign are shown in Fig 1.

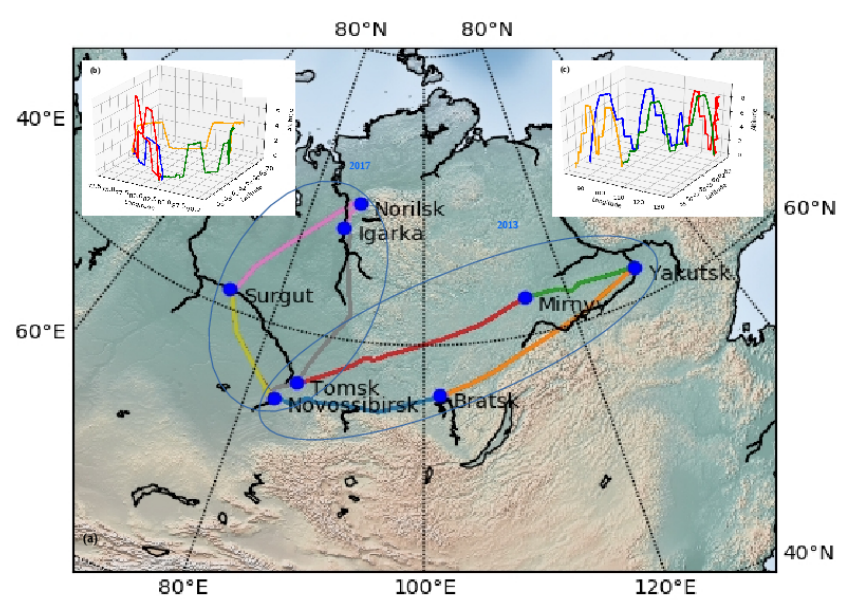

Fig. 1: Map of the 8 aircraft flight tracks carried out in 2013 (eastern loop) and in 2017 (northern 
loop). The aircraft altitude ranges are also shown for the 2017 (b) and 2013 (c) flights.

The flights were selected to fly over (i) the major Siberian cities (Novosibirsk, Tomsk, Krasnoyarsk, Yakutsk) (ii) the gas flaring fields of the Ob valley and the industrial city of Norilsk (iii) the Siberian taiga to sample long-range transport of forest fires and mid-latitude Eastern Asia emissions.

\subsection{Airborne lidar system}

The transmitter module is based on a solid state Nd-YAG laser emitting $8 \mathrm{~ns}$ laser pulse at $532 \mathrm{~nm}$. The optical receiver is a $150 \mathrm{~mm}$ diameter reception lens coupled with a $1 \mathrm{~nm}$ filter and two reception channels (co- and cross-polarization). The vertical sampling is less than $6 \mathrm{~m}$. The full geometrical overlap is obtained between $80 \mathrm{~m}$ and $150 \mathrm{~m}$. In practice the first $200 \mathrm{~m}$ are not used to account for lidar misalignment during the flights. The cross-polarization calibration is not good enough to characterize the aerosol type and is mainly used to discriminate cloud and aerosol layers.

\subsection{Aerosol optical depth retrieval}

The lidar calibration is performed several times during each flight using a normalization of the attenuated backscatter signal (PR2) to molecular backscatter in the range $200 \mathrm{~m}-700 \mathrm{~m}$ below the aircraft when the fit with the molecular density slope is better than $4 \%$, only at altitudes above $3.5 \mathrm{~km}$ and when no aerosol/cloud layers are seen in the calibration range. The vertical profile of molecular backscatter was estimated from the $0.75^{\circ}$ ERA-Interim ECMWF meteorological analysis.

Aerosol optical depth retrieval is based on the Fernald forward inversion of the calibrated PR2 [7], assuming a range independent value of aerosol lidar ratio (LR). The $L R$ value is constrained using the distribution of $10 \mathrm{~km}$ MODIS collection 6 aerosol optical depth (AOD) in an area of $\pm 70 \mathrm{~km}$ and a time lag of $\pm 5 \mathrm{~h}$ around the aircraft observation.

The distribution of possible LR values was recursively tuned to obtain an airborne lidar AOD within the $25^{\text {th }}$ and $75^{\text {th }}$ percentile of the MODIS AOD distribution. To estimate the uncertainty of the retrieved backscatter ratio, 500 inversions were randomly performed using the LR distribution and using a backscatter coefficient distribution at the reference altitude according to the estimated calibration error.

\section{RESULTS}

\subsection{Urban pollution case}

During the 2017 campaign, between Novosibirsk and Surgut above the Ob Valley, the aerosol vertical distribution shows 100-200 km horizontal layers in the 0 and $2.5 \mathrm{~km}$ altitude range (Fig. 2).

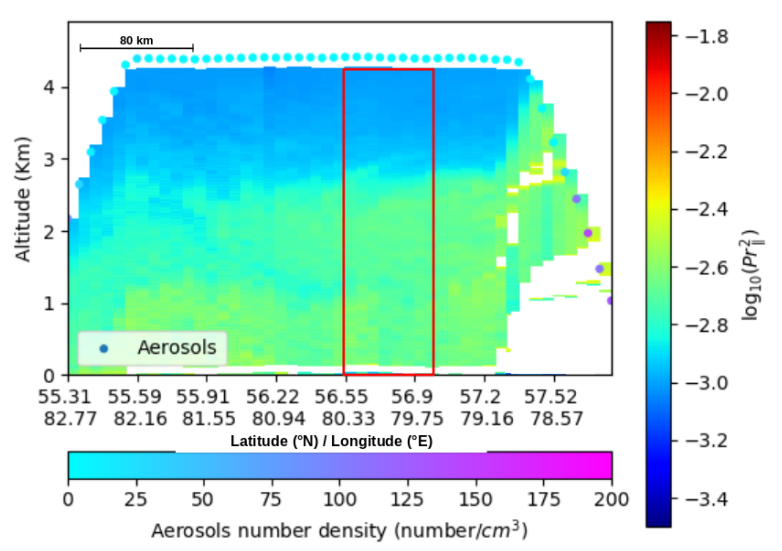

Fig. 2: Vertical cross-section of airborne lidar $\log _{10}$ (PR2) on June, 162017 . Calibration constant is $13458 \pm 2 \%$. Grimm aerosol concentrations in particle. $\mathrm{cm}^{-3}$ are shown at the aircraft altitude.

The FLEXPART simulation (Fig. 3) potential emission sensitivity (PES) is used to identify the possible aerosol sources (PES > 2000 s). Both aerosol emissions from the Novosibirsk area and from Kazakhstan can explain the layers seen by the airborne lidar.

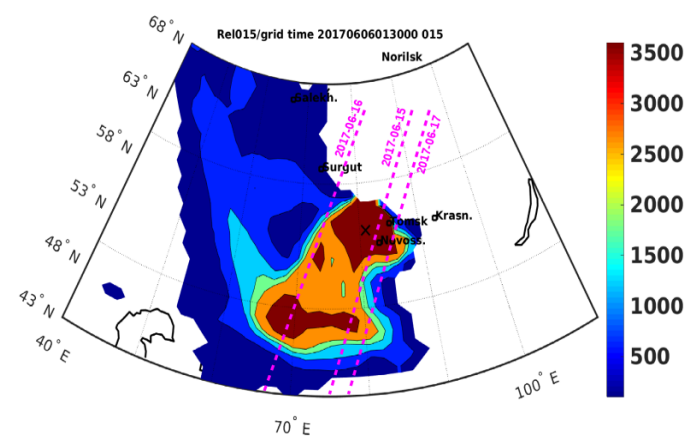

Fig. 3: Map of the PES distribution for FLEXPART backward simulation for the aerosol layers between $0-2 \mathrm{~km}$ at $56.6^{\circ} \mathrm{N}$ Fig. 2 (black 
cross). The pink dotted lines are the selected CALIOP overpasses in the source area.

MODIS AOD and tropospheric CO column measured by IASI are however higher in Northern Kazakhstan (0.15-025 AOD, 2.0-2.5 $\mathrm{x} 10^{18}$ molecule. $\mathrm{cm}^{-2}$ CO column) than in the Novosibirsk area (0.05-0.12 AOD, 1.5-1.8 x10 $0^{18}$ molecule.cm ${ }^{-2} \mathrm{CO}$ column).

No forest fires are located in the high PES areas according to the FIRMS data. A CALIPSO vertical cross-section above Northern Kazakhstan shows depolarizing aerosol layers $(>10 \%)$ up to $3 \mathrm{~km}$ altitudes between $45^{\circ} \mathrm{N}$ and $50^{\circ} \mathrm{N}$ (Fig. 4). A mixture of dust and pollution source is then expected in the layers seen by the airborne lidar at $56^{\circ} \mathrm{N}, 80^{\circ} \mathrm{E}$.

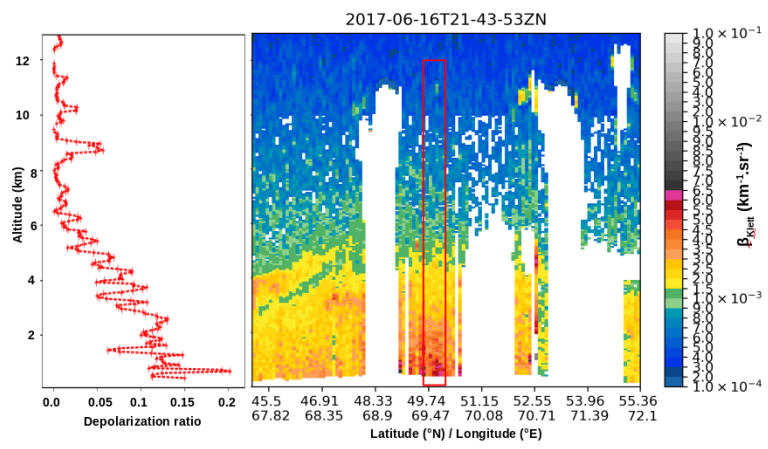

Fig. 4: Vertical cross-section of CALIOP 532 backscatter coefficient (right side) on June 16 in the Kazakhstan source region. CALIOP 532 depolarization ratio vertical profile at $49.74^{\circ} \mathrm{N}$ (left side).

The mean airborne lidar backscatter ratio at $56.7^{\circ} \mathrm{N}$ is $19 \pm 0.1$ below $2.5 \mathrm{~km}$ altitude with an AOD $_{532}$ of $0.0895 \pm 0.0225$ and LR between 26 and 40, when constrained by MODIS observations (Fig. 5). The corresponding aerosol type would be "dusty mix" according to [8]. It is also in good agreement with the FLEXPART analysis.

Two CALIOP backscatter ratio profiles in the same area at $55.5^{\circ} \mathrm{N}, 82.5^{\circ} \mathrm{E}$ on June $15^{\text {th }}$, $21 \mathrm{UT}$ and at $57^{\circ} \mathrm{N}, 87^{\circ} \mathrm{E}$ on June $17^{\text {th }}, 20$ UT are in good agreement with the airborne lidar observations. The corresponding $\mathrm{AOD}_{532}$ are $0.1 \pm$ $0.04(0.1 \pm 0.04)$ and $0.168 \pm 0.062(0.139 \pm$ 0.047) for the CALIOP L2 product (LATMOS processed L1 data) on June $15^{\text {th }}$ and $17^{\text {th }}$ respectively, with LR between 55 and 70 sr. A better match with the airborne lidar and MODIS
AOD could be obtained by using LR values smaller than 40 as expected for a dusty mix type.

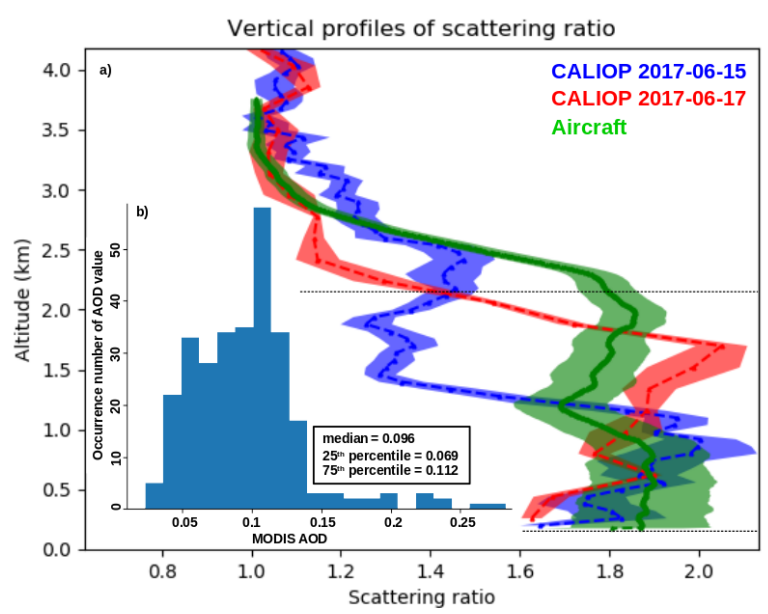

Fig. 5: (a) $50 \mathrm{~km}$ average of the backscatter ratio vertical profile for the airborne lidar on June $16^{\text {th }}$ 05 UT (green), CALIOP on June $15^{\text {th }}$ (blue) and on June $17^{\text {th }}$ (red). (b) MODIS AOD ${ }_{550}$ distribution in the $\pm 70 \mathrm{~km}$ area around the aircraft.

\subsection{Boreal forest fire case}

During the 2013 campaign, a $500 \mathrm{~m}$ thick aerosol layer is observed by the airborne lidar at $2.0 \mathrm{~km}$ between Tomsk and Mirnyy (Fig.6).

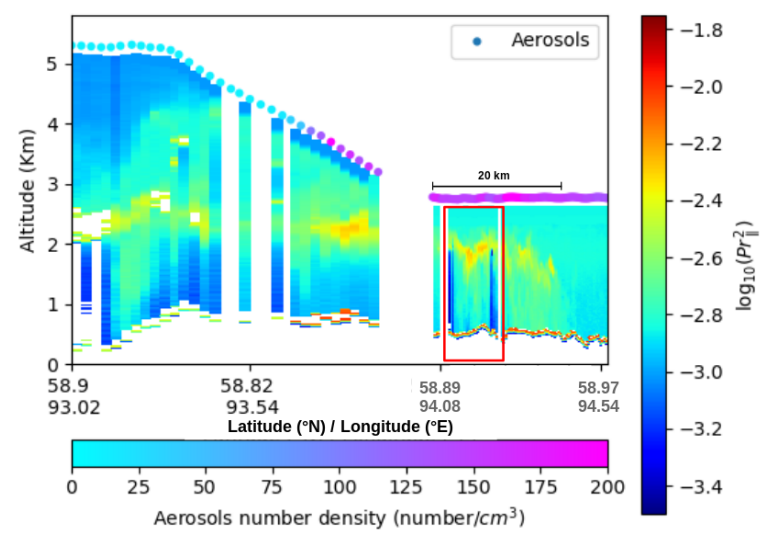

Fig. 6: Vertical cross-section of aircraft $\log _{10}(\mathrm{PR} 2)$ on July, 19 2013. Calibration constant is $491724 \pm$ $10 \%$. Grimm aerosol concentrations in particle. $\mathrm{cm}^{-3}$ are shown at the aircraft altitude.

According to the FLEXPART simulation, no aerosol transport is expected from large cities or pollution sources, while several forest fires were identified by the FIRMS data close to the aircraft position (Fig. 7). The mean airborne lidar backscatter ratio at $58^{\circ} \mathrm{N}$ (Fig. 6) is larger than 3.0 
between 1.5 and $2.2 \mathrm{~km}$ altitude with an $\mathrm{AOD}_{532}$ of $0.122 \pm 0.022$ and LR between 53 and 56, when constrained by MODIS observations. Such values are consistent with a "fresh smoke" aerosol type according to [8].

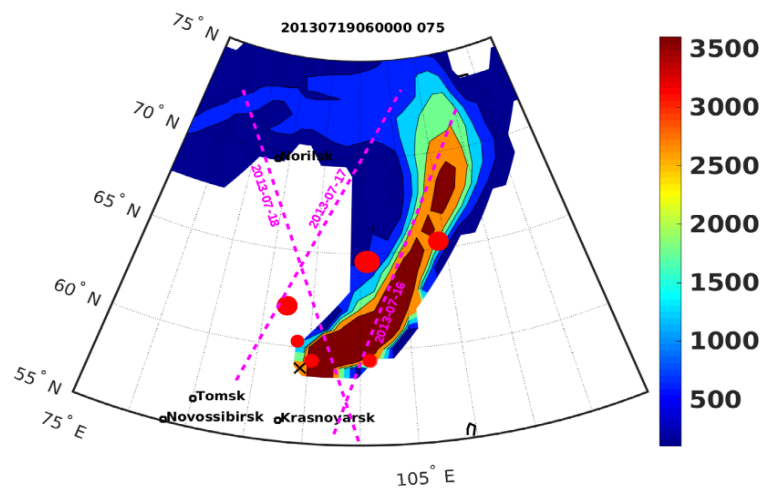

Fig. 7: Map of the PES distribution for FLEXPART backward simulation for the aerosol layer at $1.7 \mathrm{~km}$ Fig. 6 (black cross). The red dots are FIRMS forest fires and the pink dotted lines are the selected CALIOP overpasses in the source area.

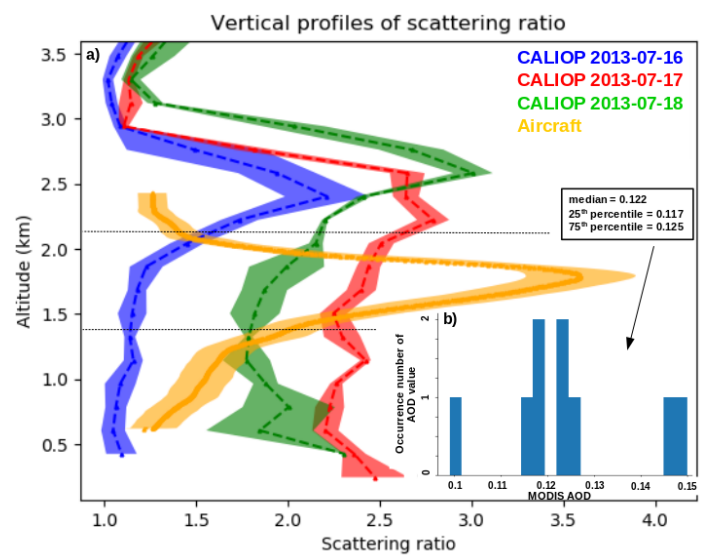

Fig. 8: (a) $20 \mathrm{~km}$ average of the backscatter ratio vertical profile from the airborne lidar on July $19^{\text {th }}$ 6 UT (yellow), CALIOP on July $16^{\text {th }} 19$ UT (blue), on July $17^{\text {th }} 19$ UT (red) and on June $18^{\text {th }} 5$ UT (green). (b) MODIS AOD 550 distribution in the $\pm 70 \mathrm{~km}$ area around the aircraft position.

This backscatter ratio profile can be compared with several CALIOP tracks observed near forest fires in the same area (Fig. 7). The CALIOP vertical profiles show smoke layers between $2 \mathrm{~km}$ and $3 \mathrm{~km}$ altitude, but with backscatter ratio between 2 and 3 (Fig. 8). CALIOP AODs in the latitude band $60^{\circ} \mathrm{N}-62^{\circ} \mathrm{N}$ range from 0.1 to 0.3 with lidar ratio of $70 \mathrm{sr}$. AODs are also in good agreement with the range of MODIS AOD around the CALIOP tracks. While the airborne lidar is able to sample fresh smoke layer, CALIOP profiles did not overpass fires during the combustion phase and are thus mainly representative of fire plumes after transport and mixing. It explains both the vertical structure of the CALIOP aerosol layers (larger thicknesses and smaller peak values) and larger lidar ratio for aged biomass plume [8].

\section{Conclusion and Perspectives}

During the 2017 and 2013 aircraft campaigns, mixed layers of dust and pollution from Northern Kazakhstan and smoke layers in forest area were detected by the airborne lidar. Comparison with CALIOP backscatter ratio shows that CALIOP algorithm may overestimate the LR for a dusty mixture if not constrained by an independent AOD measurement. The use of low liquid water cloud reflectance from the Synergized Optical Depth of Aerosols product (SODA) or land surface reflectance from the Wide Field Camera (WFC) aboard CALIOP could be a step forward to derive the aerosol CALIOP extinction above Siberia.

\section{ACKNOWLEDGEMENTS}

This work was supported by Sorbonne Université and the French Centre National d'Etudes Spatiales.

\section{REFERENCES}

[1] M.Di. Pierro, and al. Atmospheric Chemistry and Physics 11.5, 2225-2243 (2011)

[2] G. Ancellet, and al. Atmospheric Chemistry and Physics 14.16, 8235-8254 (2014)

[3] C. Di Biagio, and al. Journal of Geophysical Research: Atmospheres 123.2, 1363-1383 (2018) [4] M.H. Kim, and al. Atmospheric Measurement Techniques 11.11 (2018)

[5] L. Giglio, and al. Remote Sensing of Environment 87.2-3 , 273-282 (2003)

[6] W. Schroeder, and al. Remote Sensing of Environment 143, 85-96 (2014)

[7] F. Fernald, et al. Applied Optics 23.5, 652-653 (1984)

[8] S.P. Burton, et al. Atmospheric Measurement Techniques 6.5, 1397-1412 (2013) 